\title{
Peripheral Facial Paralysis Sequels Treated with suspension Threads
}

\section{Carrillo Rivera J1*, Autran Martínez J², Flores LR ${ }^{3}$, Caltenco Solis $\mathrm{RB}^{4}$, González Masso $\mathrm{G}^{5}$ and Gallina Amaya $\mathrm{M}^{6}$, Bello Javier $\mathrm{G}^{7}$, Esther Diana Carolina FC ${ }^{8}$ Rodriguez Daniel F9, Magaña Salcedo $J^{4}$ and Manrique Velasco EM${ }^{10}$}

${ }^{1}$ Institute of Security and Social Services for Workers of the State, Justo Sierra University, Mexico

${ }^{2}$ General dentistry practice, México

${ }^{3}$ Oral and maxillofacial surgeon, Hospital Regional de Alta Especialidad, de la Península de Yucatán. Private practice Hospital Star Médica, Mexico

${ }^{4}$ General surgeon, Hospital “Dr. Darío Fernández Fierro”, Mexico

${ }^{5}$ Oral and maxillofacial Surgeon, Private Practice, Hospital Merlos, Mexico

${ }^{6}$ Orthodontist, Private Practice, Hospital Merlos, Mexico city

${ }^{7}$ Oral and Maxillofacial Surgeon, Mexico

${ }^{8}$ Oral and Maxillofacial Surgery, Hospital Adolfo Lopez Mateos, Mexico

${ }^{9}$ Plastic and reconstructive surgery, Centro Medico Nacional, Mexico

${ }^{10}$ Otorinolarongology, Centro Médico Nacional, Mexico

*Corresponding author: Dr. Jorge Arnulfo Carrillo Rivera, Dental and Maxillofacial Rehabilitation, Office 124, Juárez Avenue, Number 8, Colonia Las Margaritas, Tlalnepantla State of Mexico, Tel: 53618677; Email: jcarrillo_99@yahoo.com

\section{Abstract}

The management of facial paralysis sequels has changed in recent years. Although the tensor threads used for facial rejuvenation, implemented with great success, returning aesthetic and symmetry. The technique for lifting was mentioned since 1956, when Buttkewitz published a correction for the nasolabial fold using a nylon thread and in 1996 by Dr. Marlen Sulamanidze, as a minimally invasive procedure that "anchor or raises" the thin facial tissue in a new position. We present a patient with peripheral facial paralysis sequels treated with suspension threads.

Keywords: Barbed sutures; Suspension threads; Gold threads; Facial paralysis sequels 


\section{International Journal of Transplantation \& Plastic Surgery}

\section{Introduction}

Among the most interesting advances in plastic surgery and facial cosmetics, the search for minimally invasive procedures and the use of small incisions, is increasing, the facial suspension threads stand out for their easy placement and good results, these threads are sutures that are implanted in the hypodermic tissues and serve to recalibrate the facial areas that present falls by gravity, help restore the contours and elevate the structures of the face [1].

Originally these threads were developed in Georgia in the Former Soviet Union - reason why they became known as "Russian threads" - they were made with metals and polymers, gold and polypropylene mainly, (gold threads) all of a permanent nature. At present, there are absorbable threads manufactured by companies that bought the original patents and that have evolved into complex materials and designs that have managed to increase their acceptance among plastic and maxillofacial surgeons at an international level. The yarns on its surface contain microscopic anchors that open after their implantation, increasing the number of collagen and elastin fibers in the area giving firmness to the tissue and producing the lifting effect $[2,3]$.

Recently we started using support wires in patients with facial paralysis due to the flaccidity of the affected hemi facial area. The indications of the support wires are very precise; they are not for all patients with sequels of facial paralysis. They are indicated in patients with mild to moderate facial ptosis or drooping (to fall), to improve expression lines (eyebrows, cheeks, etc), or used as a complement to a traditional facelift in specific areas of the face, with very good results. Indicated in patients between 35 to 50 years old, with moderate ptosis, achieved without scars, and major changes in the physiognomy of the patient and achieving "a more symmetrical look", which is the essential objective in this intervention. The estimated time of surgery is 40 minutes; to introduce the threads local anesthesia is applied.

\section{Case Report}

Female patient, 50 years old, with right facial paralysis sequels, of 5 years of evolution; treated with physical rehabilitation, pharmacological and physiotherapist, based on corticosteroids, facial massage, mimicexercises, vitamin B and hydroxocobalamin and electro-stimulation, electromyography of the facial nerve was performed, with neuropathy of the right facial nerve, on physical examination, slight palpebral ptosis was observed, nasolabial line deviated to the right side, the patient reported low self-esteem and depression due to the sequels of peripheral facial paralysis (Figures 1-3).

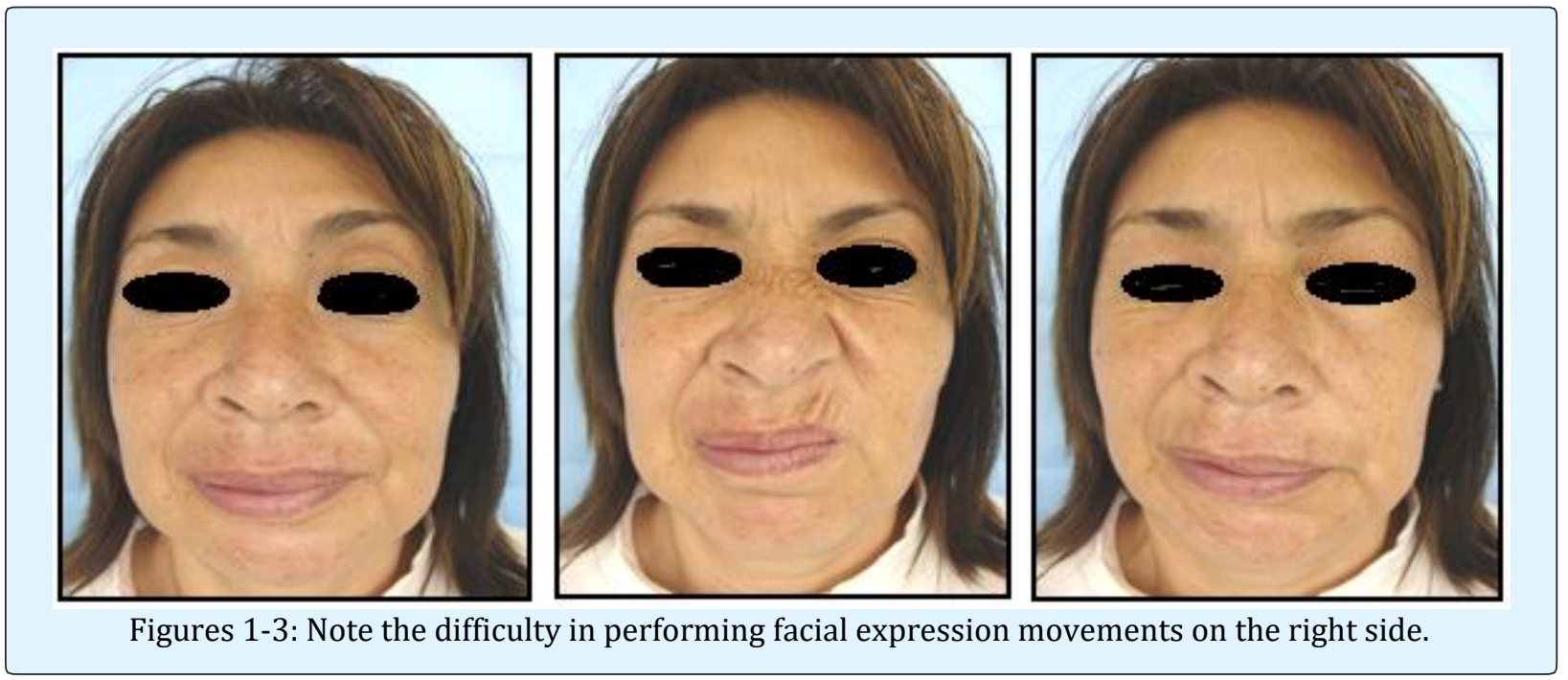

A physical examination of the facial region was performed, finding the following clinical characteristics: idiopathic facial paralysis classified by the Botman System and Jongkess as class 3 (moderate paresis), by the Smith system as scale III (50 to $70 \%$ function), and House-
Brackmann grade IV (moderate paresis), with involvement in facial expression muscles innervated by the temporal, buccal and mandibular branches of the facial nerve. 


\section{International Journal of Transplantation \& Plastic Surgery}

The procedure lasts an average of 40 minutes, does not require hospitalization, previously the patient must take anti-inflammatories and antibiotics. Performed under local anesthesia and on an ambulatory management. The threads are constituted by polypropylene that is a material that does not generate rejection or reaction in the tissues, non-toxic and highly resistant, these threads are introduced into the skin through guides, the small projections or scales are fixed to the deep tissues and then tension is applied on them, generating stretching of the area that is being handled. The surgery consists in introducing a cannula under the skin with the threads that will support the affected hemicara with flaccidity, these filaments are formed by a kind of scales that are anchored in the skin and that when stretched "pull" the flaccid area without leaving a scar (Figures 4 \& 5).

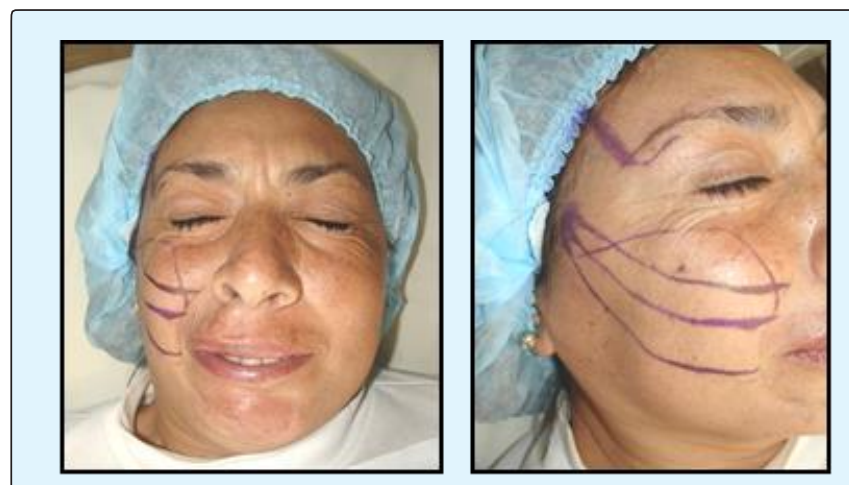

Figures 4 \& 5: Trans chirurgical photographs, marking lines for the placement of suspension threads.

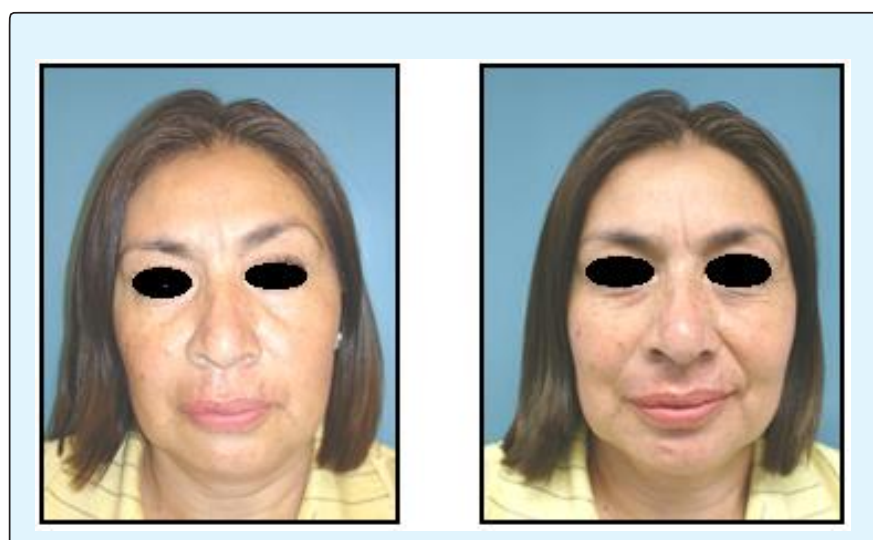

Figures 6 \& 7: Control photographs two months after surgery.
Two months after the implantation treatment of the suspension threads, the patient presented a better attitude and improvement in her self-esteem. The facial changes are significant in particular in the regions innervated by the frontal, zygomatic and buccal branches (Figures 6 \& 7).

\section{Discussion and Conclusions}

The sequels of facial paralysis are increasingly frequent, this pathology is very annoying because of the inability to control the facial muscles, the deviation of the labial commissure towards the healthy side, as well as the asymmetric appearance that for some patients is of great importance [4]. The recovery of the patient is excellent, the skin is tensed by means of this network of threads in a short time, thus perpetuating the result. The suspension threads have shown great changes in their use and function, some details such as the length, the direction of the needle and tension in the traction, require a surgical skill for its placement. The advantages for the patient are the short recovery time with a minimal presence of postoperative ecchymosis. The ease of the implant, the naturalness of the results and the potential reversibility constitute solid arguments against a major surgical proposal. Undoubtedly, other supporting thread protocols may be conceived and advances in thread quality are to be expected, offering more treatment options for patients with facial paralysis sequelae $[4,5]$.

\section{References}

1. Buttkewitz H: Die Nadetecnik der Subcutane Gewebsrafungeiner Scnittlosen Korrektur methodebei Kosmetischen Brust Und Gesichtoperationen. Zentralbl Chir 81: 1185-1956.

2. Sulamanidze MA, Fournier PF, Paikidze TG, Sulamanidze GM (2002) Removal of facial soft tissue ptosis with special threads. Drematol Surg 28: 367371.

3. Shiffman MA (2001) International College of Cosmetic Surgery. International Journal of Cosmetic Surgery and Aesthetic Dermatology 3(4): 303-305.

4. Zulch KJ (1970) Idiopathic facial paresis. In: VinkenPj, Bruyn GW (Eds.), Handbook of clinical Neurology, American Elsevier Publishing, New York, 8: 241-302.

5. Vidriales V, Carrillo J, García S (2007) Diagnóstico y tratamiento de la parálisis facial en cirugía maxilofacial. Casos clínicos y revisión bibliográfica. Odontología Actual. 


\section{International Journal of Transplantation \& Plastic Surgery}

(c) (i) 